\title{
Characterization of a Water Heating System Using Solar Collector With Conical Concentrator
}

\author{
F. P. Schneider ${ }^{1}$, C. E. C. Nogueira ${ }^{1}$, Fernando Toniazzo ${ }^{1}$, S. N. M. Souza ${ }^{1}$, J. A. C. Siqueira ${ }^{1}$, I. L. Nogueira ${ }^{2}$ \\ \& D. R. Santos ${ }^{1}$ \\ ${ }^{1}$ Universidade Estadual do Oeste do Paraná, Cascavel, Brazil \\ ${ }^{2}$ Universidade Tecnológica Federal do Paraná, Toledo, Brazil \\ Correspondence: F. P. Schneider, Universidade Estadual do Oeste do Paraná, Cascavel, Brazil. Tel: \\ 55-459-9830-7619. E-mail: Francielle.pareja@hotmail.com
}

Received: August 30, 2018

doi:10.5539/jas.v10n12p405
Accepted: September 30, 2018 Online Published: November 15, 2018

URL: https://doi.org/10.5539/jas.v10n12p405

The research is financed by Coordenação de Aperfeiçoamento de Pessoal de Nivel Superior, Brasil (CAPES).

\begin{abstract}
This study aimed to evaluate a solar water heating system for using on residences, using a solar collector with conical concentrator. The principle of light concentration in a solar collector with conical concentrator is the capture and reflection of solar radiation in the center of a tapered concentrator with internal reflective faces. The area of concentration of solar energy is occupied by a receiver with material of high thermal conductivity, properly isolated by transparent surfaces, to form the greenhouse effect, where the thermal energy is transferred to a working fluid. The characterization of the system was done through field tests to determine the efficiency in the water heating. The tests were performed considering different scenarios, which varied according to the heating system (passive and active with different water flow) and solar tracking (manual adjustment and stationary). The results showed that the scenarios with solar tracking presented an average efficiency of $12.63 \%$, which was more efficient than those presented by the fixed orientation, which was $11.44 \%$. Besides that, it was verified that the active solar heating systems were more efficient than the passive ones.
\end{abstract}

Keywords: solar energy, conical solar collector, water heating

\section{Introduction}

The increase of the energy demand has encouraged researches into energy generation technologies by renewable sources with more efficient applications in the effort to reduce the supply of non-renewable fuels. It is very important to use agriculture science to give support to small farmers. The study of different water systems can contribute to foment agribusiness in small rural areas.

In this context, the solar energy is one of the main sources of energy for the sustainable development, and has an enormous potential in Brazilian territory, as it has an incidence considered relatively high (Luiz, 2013).

The solar energy, directly or indirectly transformed into thermal energy, can be considered a good alternative for heating of water for various purposes, presenting many advantages with regard to the conventional energy sources. Efforts to the harnessing of this energy, as well as its large-scale application, have made solar heating systems cheaper and more efficient demonstrating to be a viable and competitive alternative (Aldabó, 2002; Mourão, 2007).

\subsection{Solar Geometry and Concentrators}

The solar concentrators can be applied for heating of air, water and/or generation of electric power. They can be hybrid systems that concentrate the solar energy into photovoltaic cells, being the excessive heat transferred to fluids such as air and water (Zahedi, 2011). For the correct dimensioning and using of these systems, it is necessary to know the angles of the solar geometry and the types of collectors, as shown in next items. 


\subsubsection{Angles of Solar Geometry}

Considering the apparent movement of Sun in relation to the Earth's surface, some geometrical relations are observed that are described through several angles, shown in the Figure 1.

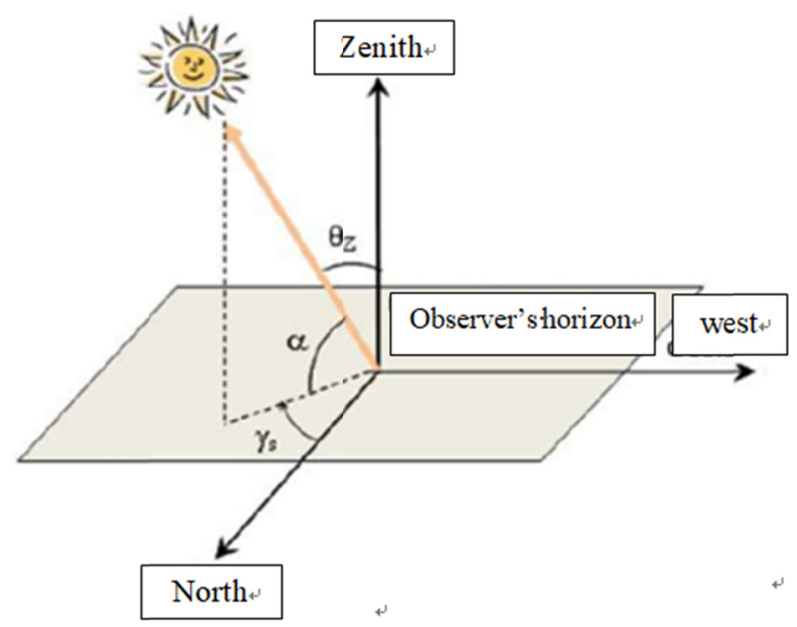

Figure 1. Representation of Sun position in relation to the horizontal plane with highlights at the reference angles (Pinho \& Galdino, 2014)

In Figure 1, it is observed the angles $\alpha, \theta_{Z}$ and $Y_{S}$ denominated Solar Altitude Angle, Zenith Angle and Solar Azimuth Angle, respectively. These angles represent the solar trajectory taking into account the apparent movement of Sun in relation to the horizon of an observer. The solar altitude $(\alpha)$, is designated as the angle between the horizontal projection of the solar rays and the incident sunlight, which is the complement of the Zenith angle $\left(\theta_{Z}+\alpha=90^{\circ}\right)$ (Duffie \& Beckman, 2006). The zenith angle $\left(\theta_{Z}\right)$ refers to the angle between the vertical (Zenith) and the solar rays, which represents the beam of radiation on a horizontal surface.

As for the solar azimuth $\left(Y_{S}\right)$, also called of azimuthal angle of the Sun, it is the angle between the projections of solar rays in the horizontal and the North-South direction (observer's horizon). In this case, the geographic North is taken as a reference $\left(0^{\circ}\right)$ when it is in the Southern hemisphere, otherwise the South is taken as $0^{\circ}$ (Northern Hemisphere). Thus, by convention, positive solar azimuth angle values are adopted when the projection is on the right of the South (to the East) and negative on the left, or on the West $\left(-180^{\circ} \leq \mathrm{Y}_{\mathrm{S}} \leq 180^{\circ}\right)$ (Pinho \& Galdino, 2014).

\subsubsection{Types of Solar Collectors}

There are basically two types of solar collectors, the non-concentrator collectors and concentrators (Duffie \& Beckman, 2006). As for the first, the solar radiation is captured as it occurs, without any concentration, reaching temperatures below $150{ }^{\circ} \mathrm{C}$. The most used collectors are the planes and the evacuated tubes. These are most used in commercial sectors (hotels, restaurants, clubs, etc.) and residences, both for water heating. As for the concentrator collectors, the solar radiation is concentrated and later absorbed as thermal energy, reaching temperatures higher than the non-concentrator collectors. The most common concentrators are the parabolic and the cylindrical-parabolic. The main applications are to the steam generation and indirect production of electric power (Mourão, 2007; Kalogirou, 2009; ANEEL, 2014; Walisiewicz, 2008).

The solar collectors can still be classified as the solar tracking system. The solar tracking systems are commonly called of solar trackers, because they monitor the positioning of the Sun during its trajectory with a certain degree of accuracy. The solar trackers can be used in systems of generation of electric energy and/or solar heating through photovoltaic modules and/or solar collectors, respectively. There are also integrated collectors that act as solar heaters and photovoltaic modules (PV/T), providing heat to a fluid and at the same time generating electric power. These systems act by withdrawing and taking advantage the heat of the photovoltaic cells, avoiding the loss of efficiency in the electric generation caused by the increase of temperature in the PV module (Rustemli et al., 2013). 


\subsubsection{Concentrator Collectors}

The concentrator collectors are devices that concentrate the solar energy and direct it to a catchment area. The solar concentrators, generally have a reflecting surface that directs the direct solar radiation to a focus where there is a receiver through which one it flows a fluid that receives the transmitted thermal energy (Kalogirou, 2009).

The use of solar concentrators is justified in cases where high temperatures are desired with the use of small catchment areas (Duffie \& Beckman, 2006).

To simplify the terminology used in these devices, some considerations are exemplified. In the case of solar concentrators, the term solar collector applies to the complete set of the heating system (including the receiver and the concentrator) (Duffie \& Beckman, 2006).

As for the receiver, it is the element of the system where the radiation is absorbed and converted into some other form of energy, which also includes the absorber, the associated cover and the isolation. Finally, the concentrator (or optical system) deals with the collector part that directs the radiation to the receiver. The concentrator is also commonly called reflector. Figure 2 shows a solar concentrator and its elements.

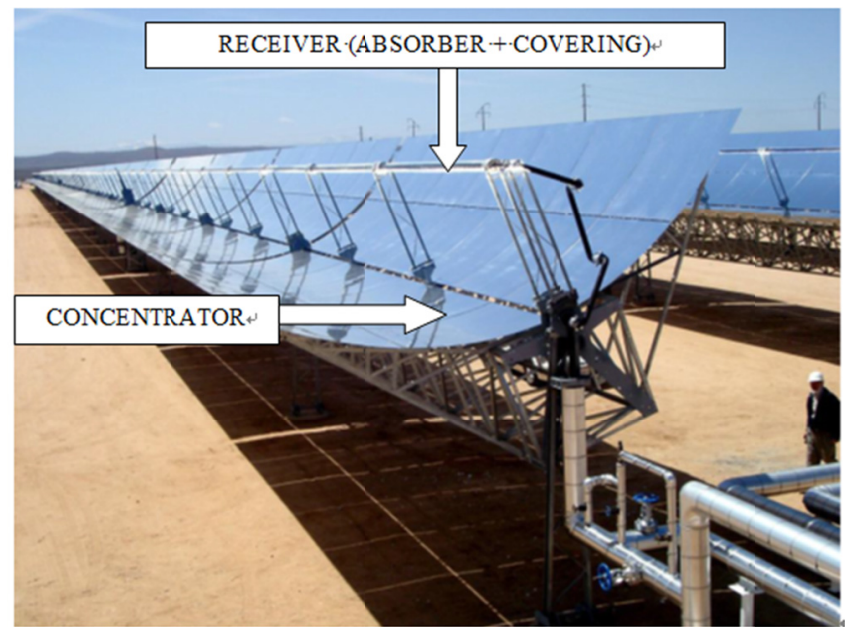

Figure 2. Example of a solar concentrator (Renewable Power News, 2009).

However, the concentrators can increase the flux of radiation on the receptors. They can be reflectors or refractors in relation to the form of light transmission. As for the geometric form, the concentrators can be cylindrical and concentrate the light in a linear or circular focus, with a focus on a point area. The receivers can be concave, plane or convex (Duffie \& Beckman, 2006). Figure 3 illustrates six possible configurations.

(a)

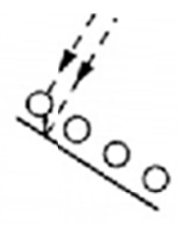

(d)

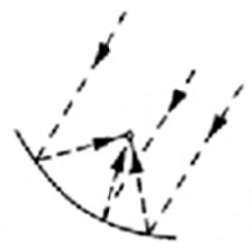

(b)

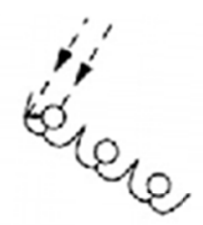

(e)

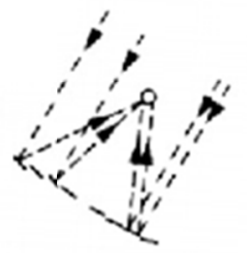

(c)
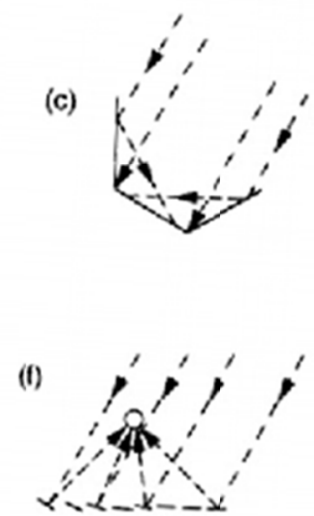

Figure 3. Possible configurations of concentrator collectors (Duffie \& Beckman, 2006)

Note. a) Diffuse reflector with tubular absorber; b) Cusp reflector with tubular absorber; c) Plane reflector with plane receiver; d) Parabolic concentrator; e) Fresnel reflector; f) Heliostat matrix with central receiver. 
Although there are several forms of configurations, the most common ones correspond to the parabolic concentrators. It is a more mature technology of thermal energy generation, reaching temperatures up to $400{ }^{\circ} \mathrm{C}$, it has its main applications in the generation of heat and in the production of electric energy (Kalogirou, 2009).

\subsubsection{Parabolic Trough Collector}

The parabolic trough collectors, also known as cylindrical-parabolic, receive this denomination according to the form of the solar concentrator. This one in turn, has the geometric shape of a parabola, and is extended longitudinally forming a trough in the field of solar reflection. Figure 4 exemplifies a cylindrical-parabolic concentrator.

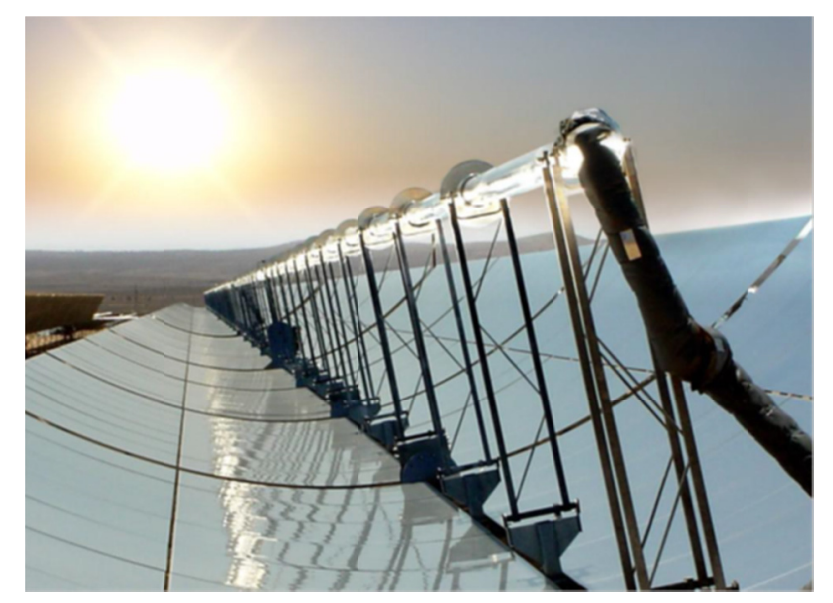

Figure 4. Cylindrical-parabolic collector (Darkoptimism, 2008)

The concentration of solar radiation in the receivers of a parabolic-cylindrical collector occurs by the reflection of the solar rays that reach the concentrator (reflector). The concentrator, in its turn, is composed or coated by a high reflection material, which reflects the solar radiation along a line of focus. In the way, the receiver is located along the linear focus in order to capture the thermal radiation through a metallic tube of dark color (absorber), and covered by a glass tube. When directed towards the sun, the surface of the concentrator reflects the sunlight and concentrates in the receiver, where a fluid circulates internally (Duffie \& Beckman, 2006).

Figure 5 shows a scheme of concentration of the solar radiation in a parabolic trough concentrator.

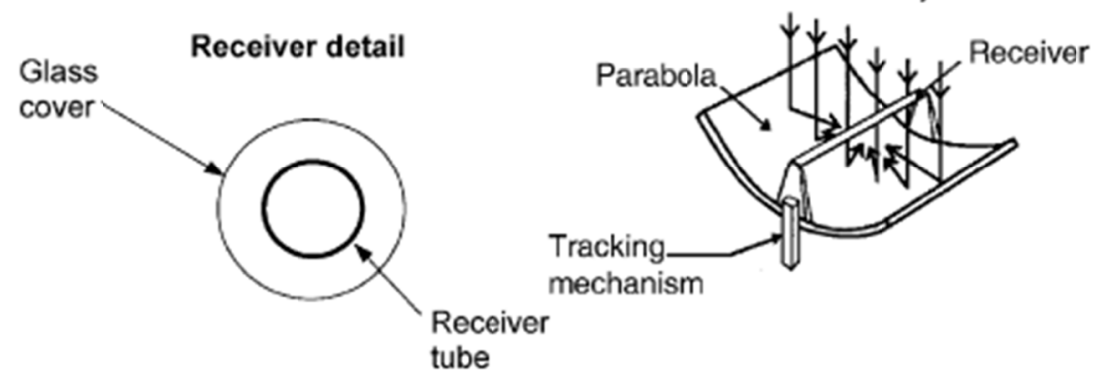

Figure 5. Reflection scheme of a parabolic trough concentrator (Duffie \& Beckman, 2006)

For a better understanding of the behavior of the solar rays, some computational models facilitate the visualization of the light reflection trajectory. A study presents the behavior of solar radiation in a parabolic trough collector for dimensioning of an absorber (Figure 6) (Xião et al., 2014). 


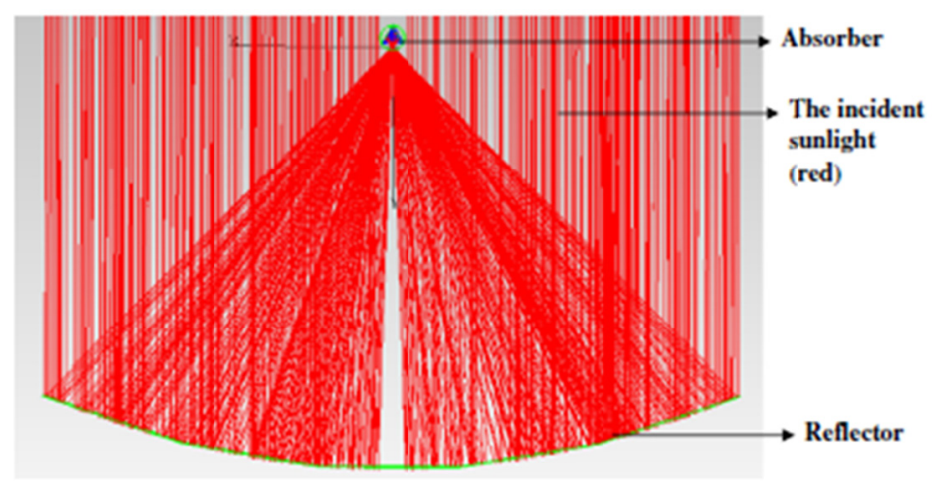

Figure 6. Light reflection scheme in a parabolic trough concentrator (Xião et al., 2014)

In Figure 6, the light incident on the concentrator (reflector) is reflected (concentrated) in a small area where the absorber is located. In the absorber circulates a type of fluid that absorbs the energy concentrated by the reflector. The parabolic trough concentrators can be categorized into two large groups with regard to their applications. The first one, and the most important, is destined to generate steam for direct and indirect use in solar plants. The temperatures reached vary from 300 to $400{ }^{\circ} \mathrm{C}$ (Figure 7). Another group can be characterized according to lower temperatures, around 100 to $250{ }^{\circ} \mathrm{C}$. Such applications are destined to the industrial processes and domestic ambient for water heating, with low temperatures and high consumption rates (Fernández-Garcia et al., 2010).

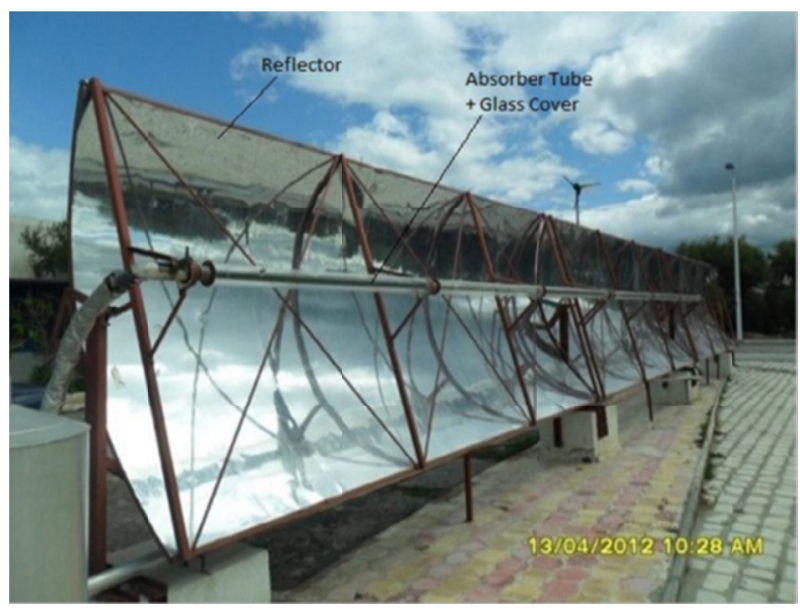

Figure 7. Parabolic trough concentrator used for room heating (Balghouthi et al., 2014)

\subsubsection{Parabolic Disk Concentrator}

The parabolic disk concentrator has this denomination according to the shape of the solar concentrator. Such concentrators are of point focus, according to the surface of revolution created by the parabola (Duffie \& Beckman, 2006).

The parabolic disk concentrators have a dynamic that allows the solar tracking in two axes, being able to maintain its perpendicularity in relation to the solar rays since the sunrise to the sunset (Duffie \& Beckman, 2006). Figure 8 shows a scheme of the solar concentration in these collectors. 


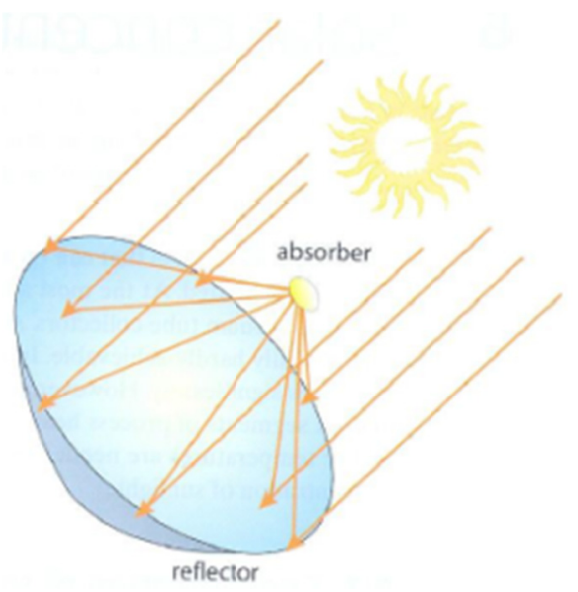

Figure 8. Solar concentration scheme in a parabolic disk concentrator (DGS, 2005)

In the same way as in parabolic trough concentrators, it can be noticed in Figure 8 that when reaching the concentrator (reflector), the solar radiation is reflected to the receiver where is situated the absorber, through which one flows a fluid. What distinguishes both concentrators is the formation of the focus, being point in the parabolic disk, whereas in the parabolic trough concentrator it is linear. Light concentration diagrams in collectors are essential for dimensioning the receiver/absorber. Figure 9 shows a solar concentrator of parabolic disk with conical absorber.

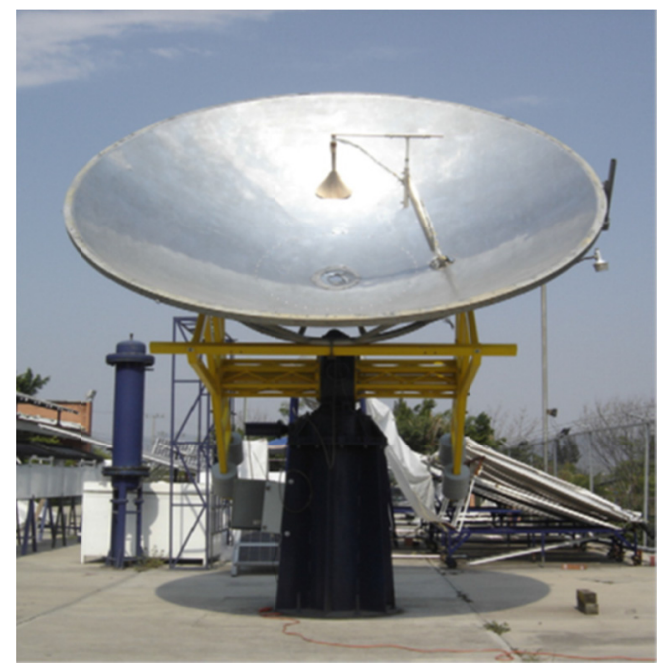

Figure 9. Solar concentrator of parabolic disk with conical receiver (HERNÁNDEZ et al., 2014)

The parabolic disk concentrators, because they have point concentration and they are solar tracked on two axes, they are highly efficient, reaching temperatures from 100 to $1500^{\circ} \mathrm{C}$. Due to the high temperature range, it can be used for steam generation and later transformed into electricity, or generate electric power directly through a generator attached in the receiver. The latter one is more interesting for avoiding thermal losses (Duffie \& Beckman, 2006).

Figure 10 shows a parabolic disk concentrator for the generation of isolated power. 


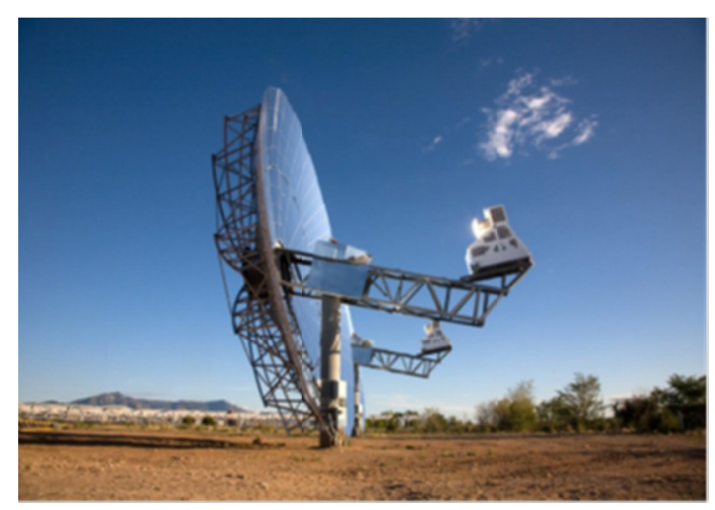

Figure 10. Parabolic disk concentrator (Global Nevadacorp)

\subsubsection{Conical Solar Collector}

The conical solar collector has such denomination according to the geometry of the solar concentrator obtained by a surface of revolution of a conical segment.

Figure 11 shows a basic form of a conical concentrator.

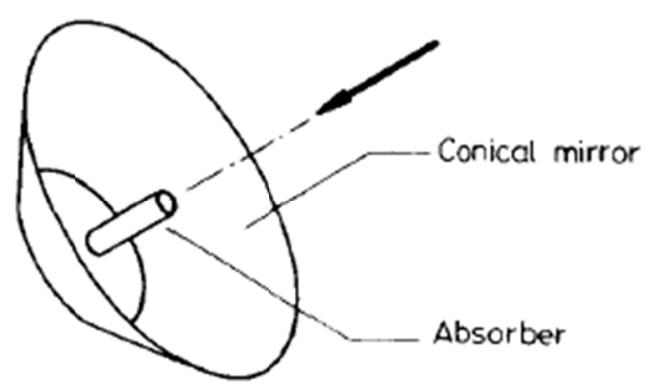

Figure 11. Scheme of a conical solar collector (El-Refaie, 1982)

In Figure 11 it is shown the main parts of the conical collector, where it can be noticed the concentrator in shape of cone trunk and the absorber located in the focus line. Even it is little widespread in relation to the conventional concentrator collectors, recent researches show the potential of conical solar collectors to generate thermal energy for heating fluids (Xiaodi et al., 2010; Kaiyan, 2009; Togrul \& Pehlivan, 2003; Hussain \& Lee, 2014) .

Despite the researches about the conical collector arouse more interest nowadays, theoretical studies about concentrators of this type are older. Some studies (Cobble, 1963; Wijeysundera, 1977; El-Refaie, 1982) presented analyzes about the theoretical performance of conical solar concentrators. These studies refer to the dimensioning of the geometry and optical efficiency of concentrators, receivers and absorbers, among other parameters, which characterize the concentration of solar energy in conical collectors.

The conical solar concentrators, as well as the parabolic-cylindrical concentrators present linear focus shapes (Luiz, 2013).

Figure 12 shows the behavior of light rays with incident angles varying from 0 to $15^{\circ}$ in relation to the axis of symmetry of a conical concentrator. 

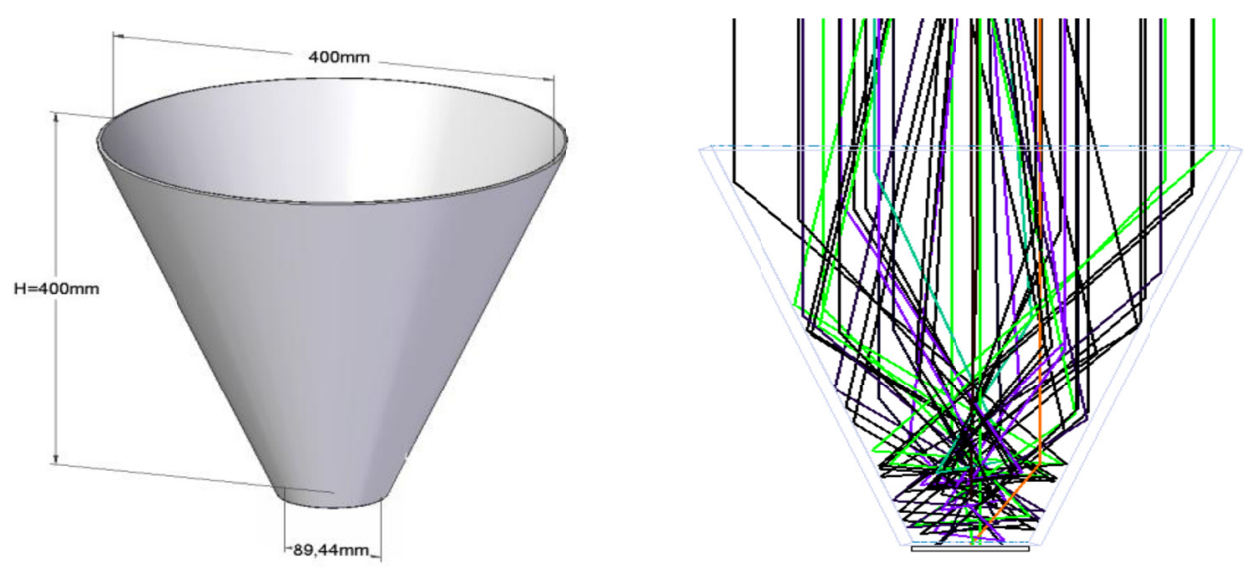

Figure 12. Behavior of light reflection in a conical concentrator (Ali et al., 2012)

The conical concentrator, as shown in Figure 12, has the advantage of admitting certain degrees of deflection at the angle of light incidence, making it possible to model the absorber to receive the concentrated radiation with reduced movements of the solar tracker. Inclinations in the angle of incidence are allowed around $15^{\circ}$ (Figure12). Some collectors with conical concentrators were adapted to converge to the concentration of light in small areas. These concentrators are denominated in the literature as light concentrator funnels. The funnel collectors are designed by the revolution of a parabola segment and its focus is concentrated in a similar way to the conics. Figure 13 shows a two-dimensional diagram of the light path in a light concentrator funnel.
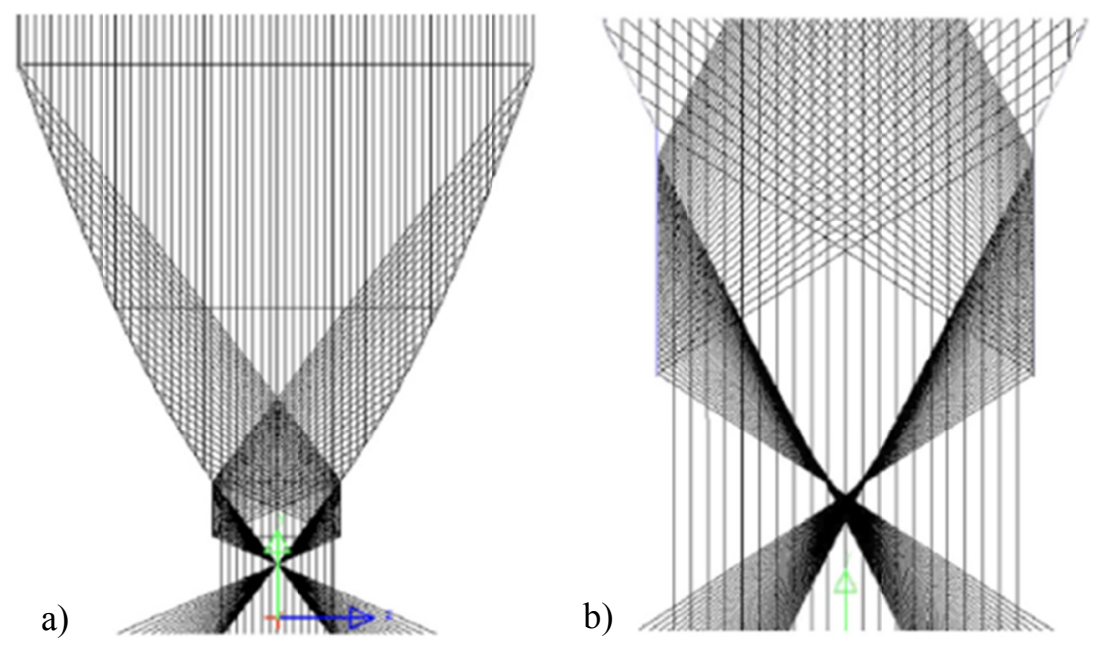

Figure 13. a) Trajectory of light in a concentrator funnel; b) Zoom of the focal point

It is noticed, in Figure 13a, that a slight curvature on a conical revolution surface can drastically change the behavior of light reflection. In the case, the incident rays perpendicular to the catchment plane of the concentrator are first reflected by the parabola segments of the concentrator, and subsequently reflected secondarily by the lower plans, converging at a point at the lower end of the concentrator. It can be noticed that the focus becomes only point according to the second reflection of the plane sides (profile of a cylinder), that is, the light concentrator funnel has a linear focus. Finally, the light concentrator funnel only presents a point focus in its first reflection, if the upper opening angle of the concentrator is very large, about it has the shape similar to a parabola, that is, to obtain the form of a parabolic disk.

Mathematical models for simulation of light concentration in photovoltaic cells (PV) are presented in (Zahedi, 2011). 


\section{Development of Solar Collector With Conical Concentrator}

This work was carried out in the municipality of Francisco Beltrão, southwest of Paraná (latitude $26.05^{\circ}$ South, longitude $53.04^{\circ}$ West and altitude $650 \mathrm{~m}$ ). According to the classification of Koppen, the region is subtropical (cfa), it has hot summers $\left(>22{ }^{\circ} \mathrm{C}\right)$, mild winters $\left(>-3{ }^{\circ} \mathrm{C}\right)$, annual sunshine of 2338 hours and annual mean of solar radiation of $2.30 \mathrm{kWh} \mathrm{m}^{-2}$ (IAPAR).

The work consisted in the construction of a solar collector prototype, to evaluate the geometric characteristics of the funnel solar collector (conical), so called according to the geometric characteristics of the light concentrator, and for obtaining its efficiency for using in water heating systems.

\subsection{Prototype of the Solar Collector}

The prototype of solar collector constructed and evaluated is shown in Figure 14.

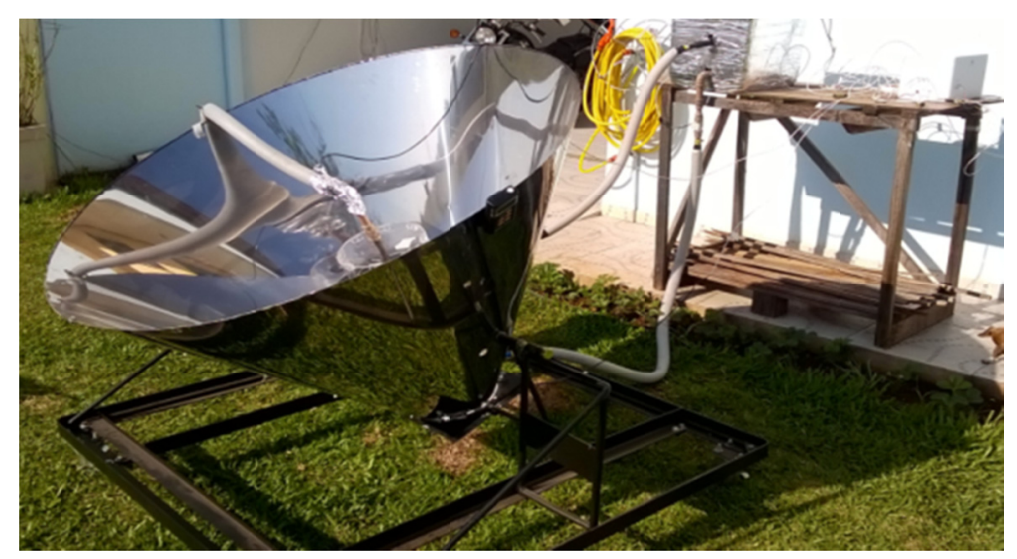

Figure 14. Funnel solar collector

The solar concentrator, shown in Figure 14, is composed of a stainless steel sheet and has a conical shape, which has the function of directing the incident solar radiation in the upper opening to the absorber, which has a serpentine obtained by the curvature of a flexible copper duct $(16 \mathrm{~mm})$, where circulates the fluid to be heated (water).

The arrangement of the set concentrator/absorber is presented under a 3D view of the funnel solar collector, with the absorber located inside the conical concentrator (Figure 15).

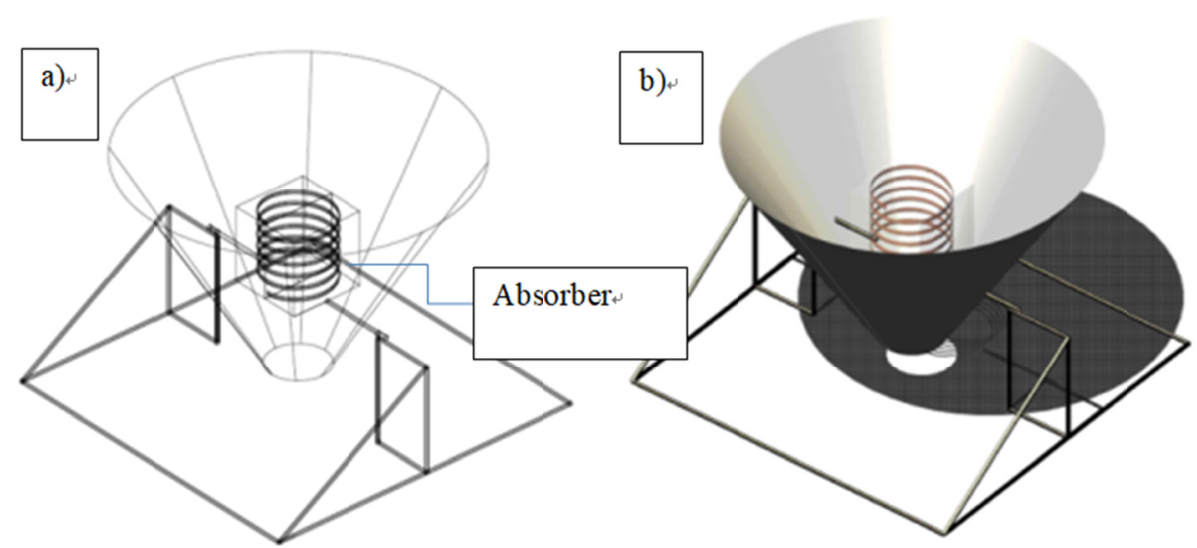

Figure 15. a) View of the solar collector in 3D; b) Simulation of the real heating system

Figure 16 shows an example of application of the funnel solar collector as a passive water heating system, in other words, operating by thermosyphon. 


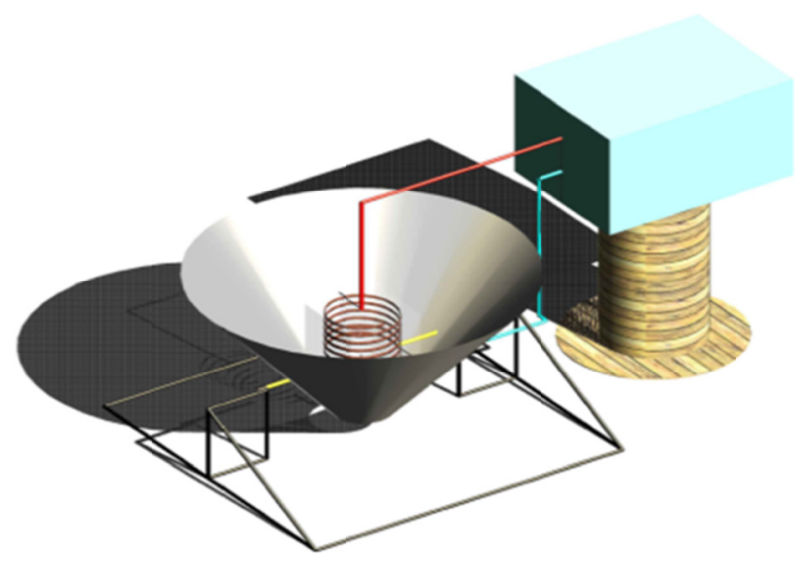

Figure 16. Scheme of the solar collector operating with thermosyphon

Considering the solar trajectory, the set concentrator/absorber presents a dynamic for solar orientation, to adjust the azimuth angle or the solar inclination (Figure 17).

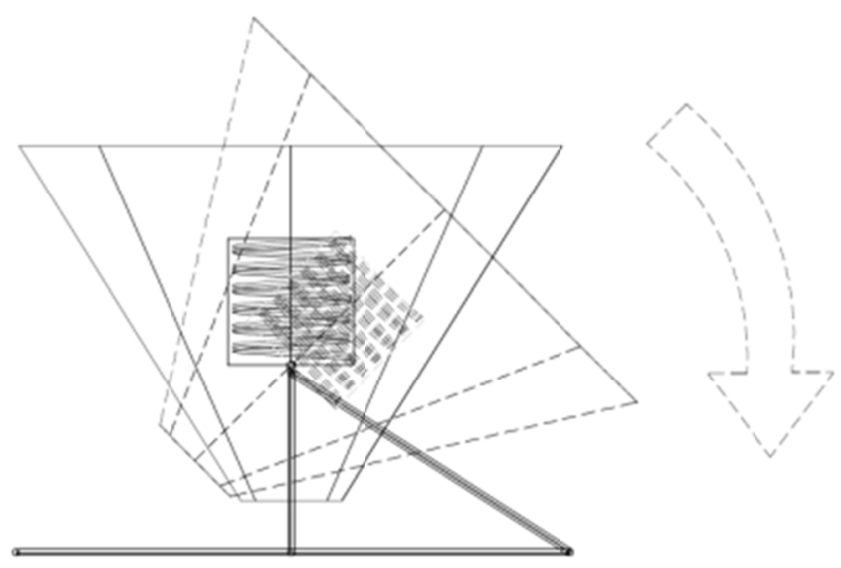

Figure 17. Side view of the concentrator and absorber dynamics (rotation)

The absorber was designed by the curvature of a flexible copper tube $(16 \mathrm{~mm})$, its final shape is similar to a serpentine. The copper serpentine was covered by a layer of dull black paint to increase the heat gain. The choice of the material was made due to the high thermal conductivity of the copper $\left(\sim 400 \mathrm{~W} \mathrm{~m}^{-1} \mathrm{~K}^{-1}\right)$. Figure 18 shows the absorber set.

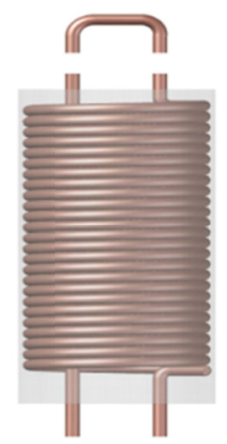

Figure 18. Absorber set 


\subsection{Instrumentation for Data Acquisition}

The data needed to evaluate the efficiency of the solar collector were obtained with the aid of a microprocessed electronic board (Arduino), connected to sensors for measuring of some variables of the solar heating process.

The sensors coupled in the Arduino are designed to measure variables that can interfere in the efficiency of the heating system, such as: water temperature, ambient temperature and mass flow.

To store the temperature and mass flow data it was used an SD card module with 8GB memory. Another variable measured was the global solar irradiation, through the use of a pyranometer with silicon photovoltaic sensor of high stability.

\subsection{Evaluation of the Solar Collector}

The characterization of the system was performed from field tests, where data were collected (solar radiation, water flow, water and ambient temperature) in different scenarios, which are basically distinguished by the dynamics of the solar collector (fixed and with manual follower), and by the function of the types of heating systems used (passive and active).

\subsubsection{Solar Collector With Passive System (Thermosyphon)}

Figure 19 shows the arrangement of the sensors installed to measure the temperature of water at different points in the solar collector, operating with passive system (thermosyphon).

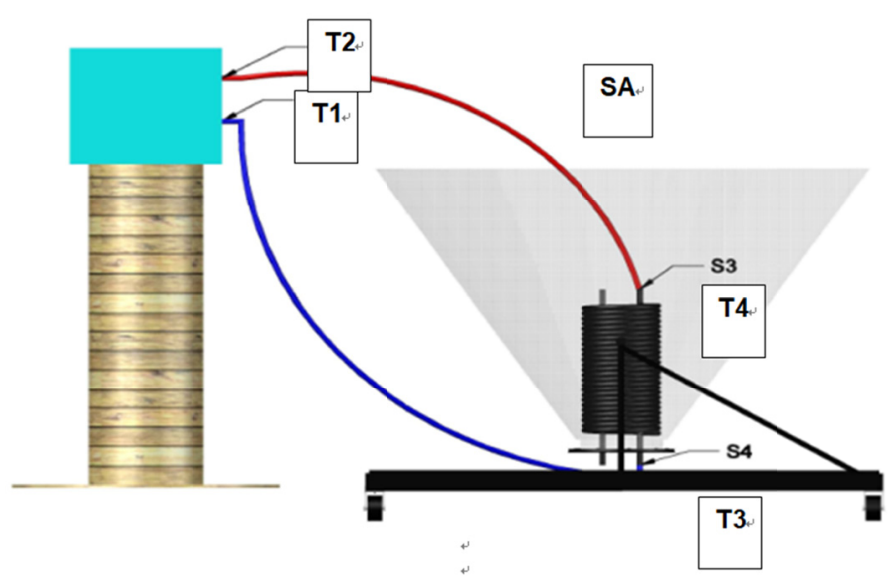

Figure 19. Layout of the sensors for measuring of the water temperature

Note. T1: Exit of the "cold" water of the thermal reservoir; T2: Entry of the heated water in the thermal reservoir; T3: Entry of the "cold" water in the absorber; T4: Exit of the heated water from the absorber; SA: Junction for the connection of the active system (when it is the case).

It is noticed in Figure 19, the points where the water temperature sensors were installed. The sensors T2 and T4 are arranged in order to collect the temperature of the heated water by the absorber, and to measure the loss of heat in the duct between the absorber and the thermal reservoir. Likewise, the sensors T1 and T3 determine the water temperature that enters in the absorber and the loss of heat in the lower duct. The pair of sensors T3 and T4 determines the rate of heat gain in the passage of the fluid in the absorber. The SA junction is a connection used only for connection of the active system.

Figure 20 exemplifies the connection scheme of the solar collector with passive system. 


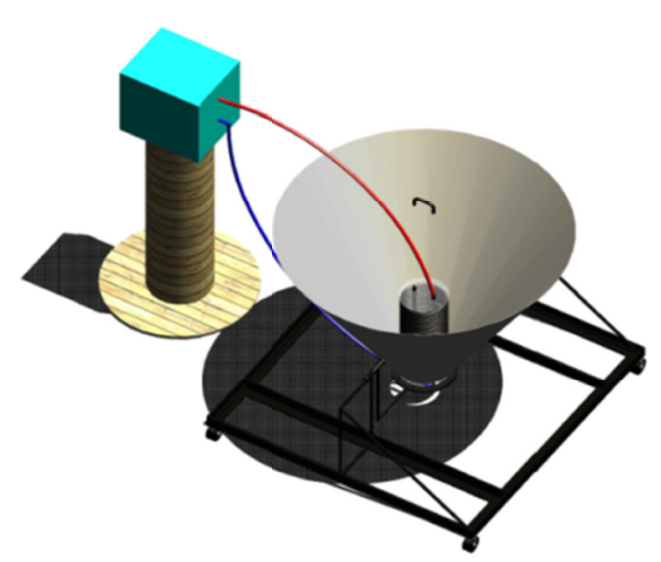

Figure 20. Solar collector operating with passive system (thermosyphon)

\subsubsection{Solar Collector With Active System (Hydraulic Pumping)}

When the SA junction is installed in the absorber, the system is operated with hydraulic pumping (active). In this configuration, it is avoided the shading generated by the upper water duct (heated water by the absorber) inside the solar concentrator. Thus, in the active system the reservoir can be stowed in the level below of the absorber (different of the thermosyphon) because the fluid circulation is performed of forced way (water pump).

Figure 21 shows the collector with active system (hydraulic pumping).

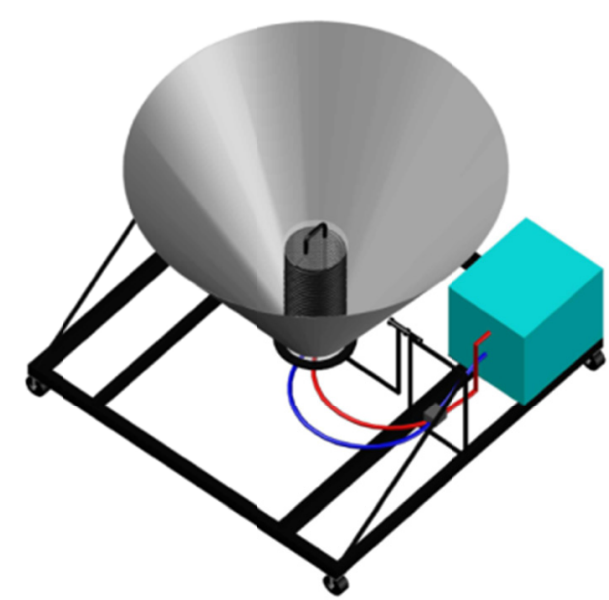

Figure 21. Solar collector operating with active system.

Figure 22 shows the trajectory of the fluid propelled by the water pump in the hydraulic circuit. 


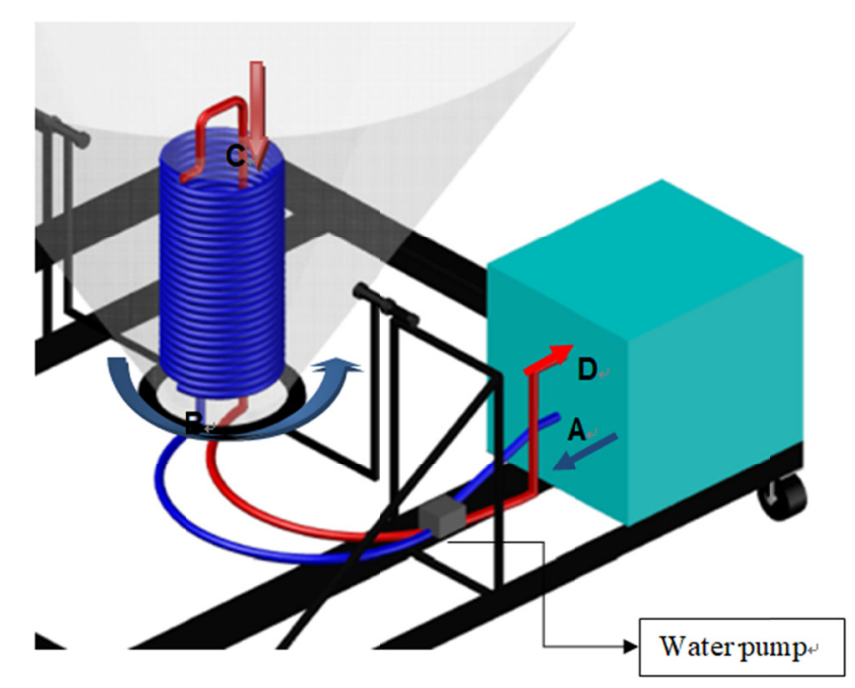

Figure 22. Detail of the water circulation scheme in the absorber with active system

According to Figure 22, the water pump propels the fluid from the lower exit of the thermal reservoir (A) to the lower part of the absorber (B). The fluid then, circulates through the serpentine until it reaches the upper point of the absorber and then descends in the point $\mathrm{C}$, returning to the top of the thermal reservoir (D).

\subsection{Evaluated Scenarios}

Both heating systems (active and passive) were submitted to different scenarios, with variation in the dynamics of the concentrator/absorber set.

The scenarios are detailed as follows:

Scenario 1 (PS): Passive system of solar water heating operating with manual solar tracker. In this scenario, the solar heating system is characterized by the thermosyphon water circulation and the orientation of the collector manually adjusted according to altitude and solar azimuth angles.

Scenario 2 (PE): Passive system of solar water heating operating with fix solar orientation. This scenario differs only from Scenario 1 in relation to the solar orientation, in other words, the solar collector fixed at $0^{\circ}$ for the solar azimuth and the inclination of the solar capture plane optimized for midday (solar altitude).

Scenario 3 (A12S): Active system of solar water heating operating with minimum flow and manual solar tracker. The forced circulation (hydraulic pumping) is the only difference in this scenario in relation to Scenario 1. The value adopted for the mass flow will be close to $4 \mathrm{~L} \mathrm{~min}^{-1}$ according to the electric voltage (12 V) of the pump supply.

Scenario 4 (A12E): Active system of solar water heating operating with minimum flow and fixed solar orientation. Idem to Scenario 3, it differs only in relation to the solar orientation, which remains fixed.

Scenario 5 (A24S): Active system of solar water heating operating with maximum flow and manual solar tracker. Scenario represented by the forced circulation system with manual tracker. The mass flow adopted will be close to $6 \mathrm{~L} \mathrm{~min}^{-1}$ according to the electrical voltage of the pump supply (24 V).

Scenario 6 (A24E): Active system of solar water heating operating with maximum flow and fixed solar orientation. Idem to Scenario 3, presents difference only in the value of the mass flow $\left(6 \mathrm{~L} \mathrm{~min}^{-1}\right)$.

The choice of the mass flow values ( 4 and $6 \mathrm{~L} \mathrm{~min}^{-1}$ ) is based on the heating system proposed by (Hussain \& Lee, 2014).

Data from each scenario were collected from 9 am to $3 \mathrm{pm}$.

\subsection{Projections and Optical Tests of the Light Reflection in the Concentrator}

In order to estimate the reflection path of sunlight incident in the conical concentrator, some projections were made. These projections are references for dimensioning the absorber and its location inside the concentrator, through the trajectory of the reflected sunlight. It was adopted Angles of inclination of the solar rays of 0,15 and $30^{\circ}$ with respect to the axis of symmetry of the conical concentrator, due to the opening angle of the cone. 
In addition to the projections and field experiments, some optical tests were performed to estimate the behavior of the light trajectory reflected by the concentrator and emitted in the absorber. The tests were made with artificial light, made with a blue-colored LED lamp ( $2 \mathrm{~W})$ and a green manual laser $(5 \mathrm{~mW})$.

The optical tests were performed under two angles of inclination of the lamps in relation to the axis of symmetry of the concentrator $\left(0\right.$ and $\left.30^{\circ}\right)$. A white cylinder of $200 \mathrm{~mm}$ was placed inside the concentrator, in order to represent the absorber and act as a developer so that the points of concentration of the reflected light can be identified.

\subsection{Positioning of the Solar Collector in Study Areas}

The efficiency of concentrator collectors is closely related to the correct orientation of the systems, so that the light reflected by the concentrator reaches the absorber. According to this, it is important to know the proper orientation of the collectors by calculations of the solar trajectory, as well as to know the angles of the solar geometry. In order to determine the angles of the solar geometry of the study site, it was used the methodology of (Duffie \& Beckman, 2006), which describes the values of altitude and solar azimuth.

\subsection{Efficiency of the Water Heating System}

The efficiency of the system was calculated by means of the ratio between the exit energy of the system (thermal energy) and the entry energy (solar energy). The Equation 1 was used to calculate the efficiency of the water heating system (Xiaodi et al., 2010; Kaiyan et al., 2009; Hussain \& Lee, 2014).

$$
\eta=\frac{\mathrm{m} \cdot \mathrm{cp} \cdot(\mathrm{To}-\mathrm{Ti})}{\mathrm{A} \cdot \mathrm{I}} \times 100
$$

Where, $\mathrm{m}=$ water mass flow $(\mathrm{kg})$; $\mathrm{cp}=$ specific heat of water $\left(=0.001163 \mathrm{kWh} \mathrm{kg}^{-1}{ }^{\circ} \mathrm{C}^{-1}\right)$; To $=$ water exit temperature $\left({ }^{\circ} \mathrm{C}\right) ; \mathrm{Ti}=$ water entry temperature $\left({ }^{\circ} \mathrm{C}\right) ; \mathrm{A}=$ solar collecting area of the concentrator $\left(=1.327 \mathrm{~m}^{2}\right) ; \mathrm{I}=$ total solar energy $\left(\mathrm{kWh} \mathrm{m}^{-2}\right) ; \eta=$ Efficiency $(\%)$.

\section{Evaluation of Solar Collector With Conical Concentrator}

\subsection{Projections of Light Reflection and Dimensioning of the Absorber}

According to the principles of optical physics and the law of light reflection, we can estimate the trajectory of sunlight incident in the concentrator. Figure 23 exemplifies a two-dimensional view of the reflection of the solar rays across the reflecting internal surface of the conical concentrator studied.

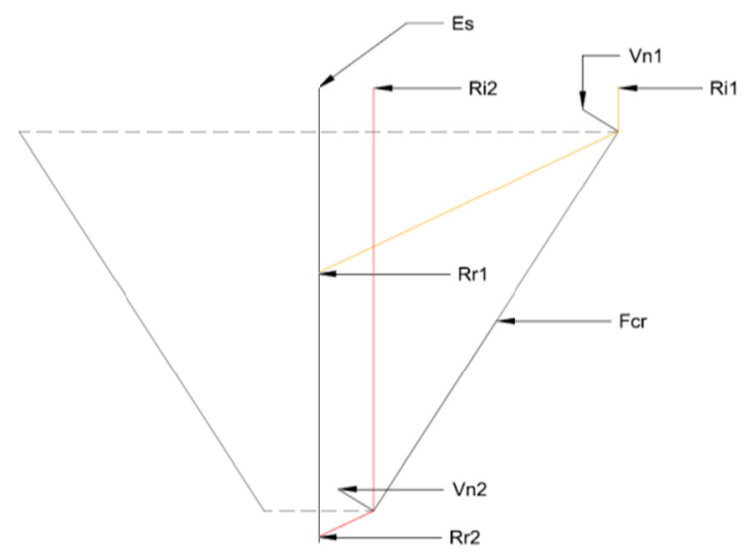

Figure 23. Scheme of the reflective area by the conical concentrator

Note. Es: Axis of symmetry; Vn1: Normal vector to the surface (area vector) of the incident solar ray 1; Vn2: Normal vector to the surface (area vector) of the incident solar ray 2; Ri1: Incident solar ray 1; Ri2: Incident solar ray 2; Rr1: Solar ray 1 reflected by the cone; Rr2: Solar ray 2 reflective by the cone; Fcr: Internal face of the reflective cone.

It can be noticed in Figure 23, the incidence of two light beams, which are extremely important in the dimensioning of the absorber. These are the solar rays Ri1 and Ri2, which represent the ends of the internal reflective face of the cone (Fcr). These optical beams delimit the area that the light reflected by the concentrator reaches the absorber, delimiting a concentration field, in other words, all the reflecting face that receives light is only capable of reflecting in the limit of that field. This statement is based on the edge angle of the upper and lower ends of the 
cone. In short, the Ri1 beam reaches the upper edge of the concentrator and then it is reflected by the face of the concentrator, determining the appearance of the reflected beam $\operatorname{Rr} 1$. The angle of $\operatorname{Rr} 1$ beam is equal to the angle between Ri1 and the normal vector to the reflecting surface (Vn1). This trajectory delimits the upper strip of reflecting of the concentrator. Likewise, it can be estimated the lower end limit by analyzing the terms Ri2, Vn2 and $\mathrm{Rr} 2$. The delimitation shown in Figure 23 applies only to the light ray at an angle of $90^{\circ}$ in relation to the concentrator opening. Authors such as (Xiaodi et al., 2010; Sharaf, 2002), also used two-dimensional diagrams to estimate the solar trajectory in similar concentrators.

Due to the dynamics of the solar trajectory, a three-slope diagram was created to aid in the dimensioning of the absorber. Figure 24 presents the simulation of the deflection of sunlight at 0.15 and $30^{\circ}$ in relation to the axis of symmetry of the cone.

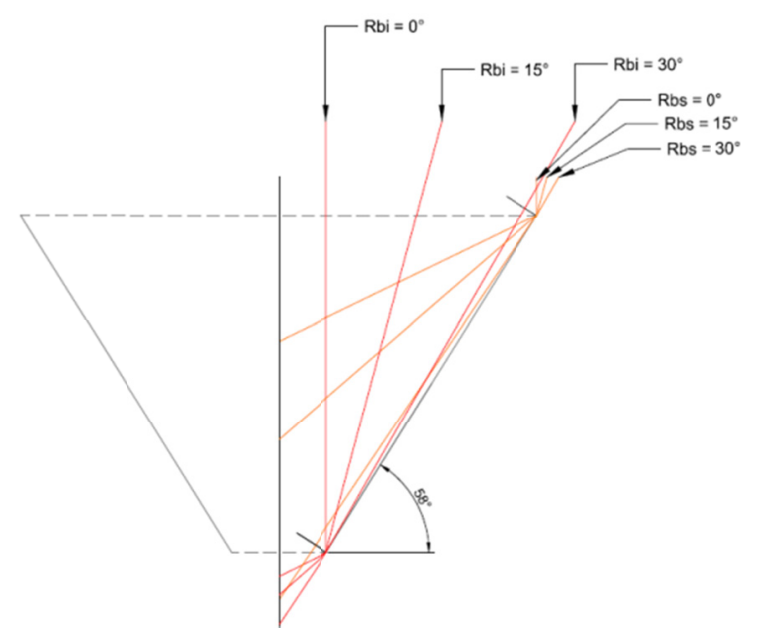

Figure 24. Projections of reflection from different edge angles

It can be noticed in Figure 24, the wide change in the angle of reflection compared to the angle of incidence, in other words, discrete changes in the angle of incidence of the light that reaches the concentrator cause drastic changes in the inclination of the reflected light in the absorber. Due to this alteration, it was opted for the optimization of the absorber dimension that contemplated a ratio between the angles 0 and $30^{\circ}$ of solar incidence.

Considering the ideal angle of sunlight capture, Figure 25 exemplifies the symmetrical distribution of several beams of light focused and reflected by the concentrator, and intercepted by the absorber.
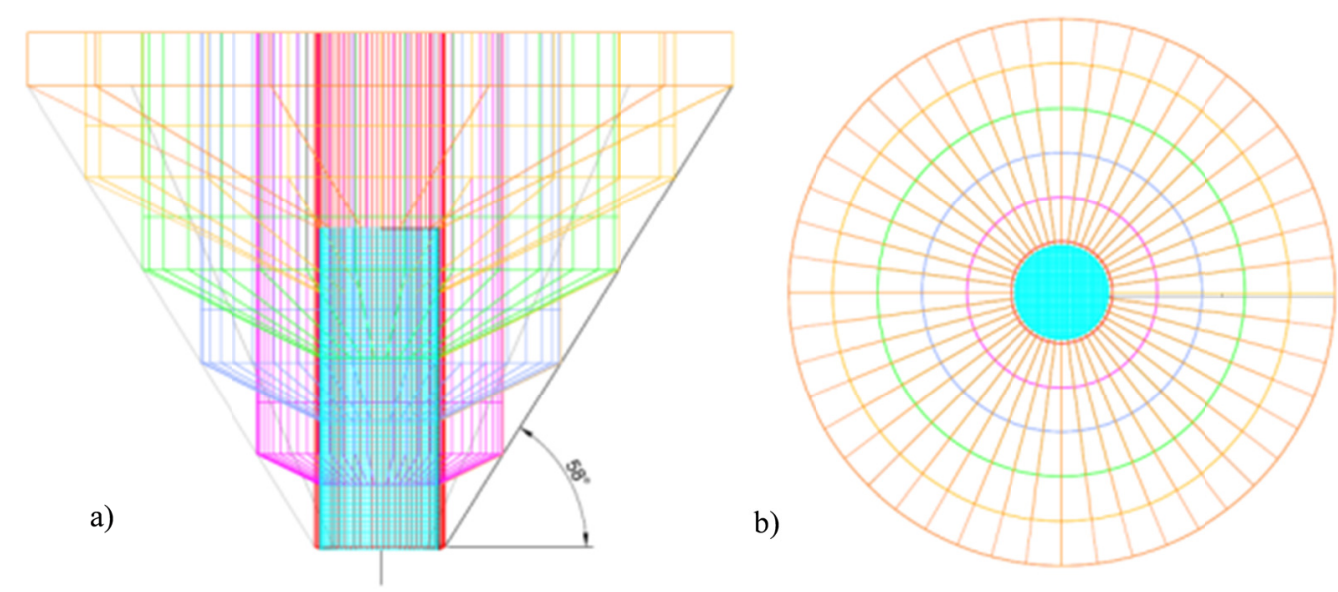

Figure 25. a) Frontal view of multiple perpendicular beams to the solar capture area; b) Upper view of the solar capture area 
It is evident in Figure 25 that under ideal light capture conditions, the interception of solar energy by the absorber is greater than the capture in deflection angles of light greater than $0^{\circ}$. Furthermore, it is realized in an integral manner that both sides of the concentrator contribute to light reflection in the absorber. However, any deflection in the angle of light incidence will result in shading of one of the faces, due to the height of the absorber.

In sum, what is perceived are linear focuses according to the conicity of the concentrator, a fact that resembles to the focus coming from cylindrical concentrator. Such linear focuses are perceived more clearly in the optical tests, shown in item the 3.2 .

Considering the simulation of light beams varying from 0 to $15^{\circ}$, it was stipulated the height of the absorber equal to $40 \mathrm{~cm}$. Such choice was conceived based on the technical limitations for manufacturing the absorber.

\subsection{Simulation of Sunlight Concentration (Optical Tests)}

Some optical tests were performed in a dark camera in order to predict the behavior of light concentration reflected by the concentrator in a practical way. Figure 26 presents the focuses shapes created by the conical concentrator with the aid of a developer that simulates the absorber. The lamp slope (blue LED) is $0^{\circ}$ in relation to the axis of symmetry of the concentrator.
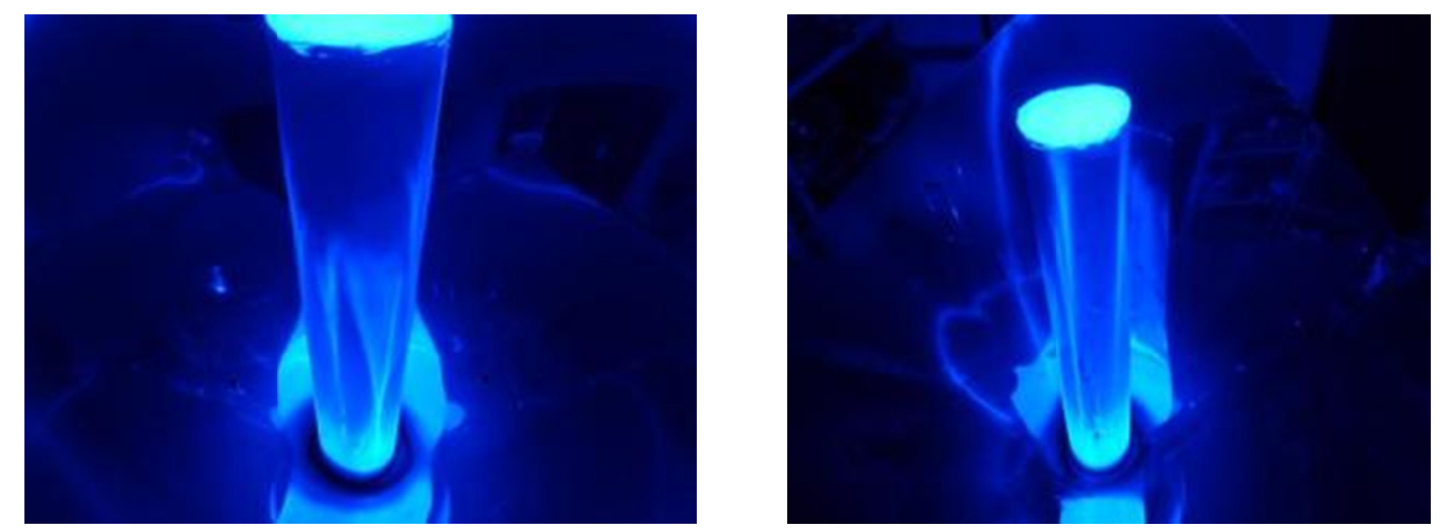

Figure 26. Optical test with blue light under equal incident light angle $0^{\circ}$

It can be noticed in Figure 26, the formation of linear focuses according to the conical shape of the concentrator. This linear formation also occurs in parabolic-cylindrical solar concentrators, according to the curvature of the concentrator. However, besides the formation of a linear focus, it is noticed that due to the conicity of the concentrator, the greater concentration of light occurs near the lower opening of the concentrator.

The optical tests provided an estimate to obtain a margin of clearance between the adjustments of the angular values of the solar azimuths in the field tests.

\subsection{Solar Collector Trails Conducted in the Field}

The evaluation of the solar collector was performed experimentally considering the proposed scenarios. The data collected in the field were related to the water temperature (four points), mass flow and the solar radiation, which were collected in a period of six hours (09:00-3:00 hours).

\subsubsection{Solar Radiation}

Throughout all the trials done, the solar radiation was the main factor that directly influenced in the thermal energy gain of water in the solar heating systems. Figure 27 presents the solar radiation values accumulated for all the scenarios evaluated. 


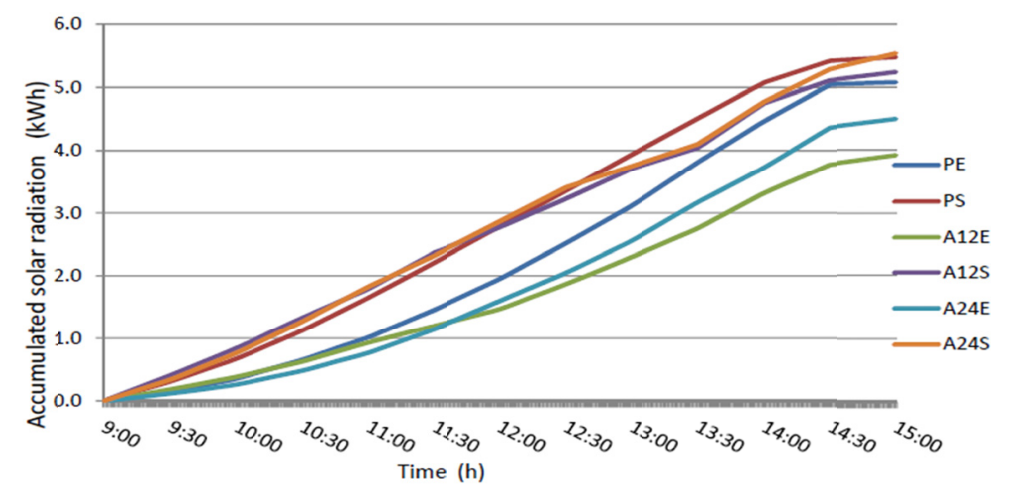

Figure 27. Accumulated solar radiation for all Scenarios

In Figure 27, it can be noticed that the values of solar radiation incident in the solar collector are close to the expected global radiation indices for the Brazilian territory, which vary from $4.25-6.5 \mathrm{kWh} \mathrm{m}^{-2}$ (IAPAR). In this context, it is observed that the highest solar energy indices were obtained in the systems with solar tracker (PS, A12S and A24S) presenting higher value in Scenario 5 (A24S). As the trails were performed on predominantly sunny days and in a period of three months, there was little influence of seasonality during de trials.

However, it is noticeable in Figure 27 that the accumulated solar radiation indices were lower in the scenarios with fixed or stationary solar orientation (PE, A12E and A24E). This is due to the fact that the solar concentrator is oriented in a position optimized to receive radiation in a specific period of the day, in other words, only in the period with the highest index of solar radiation (midday). In this way, the solar radiation is better used in the periods that coincide the orientation of the solar concentrator with the position of the solar angles.

\subsubsection{Useful Energy}

The Useful Energy considered in the trials of water heating is referring to the heat harnessed by the fluid. In other words, it is the thermal energy harnessed by the water coming from the solar radiation incident in the concentrator. Figure 28 presents the behavior of Useful Energy for all the scenarios.

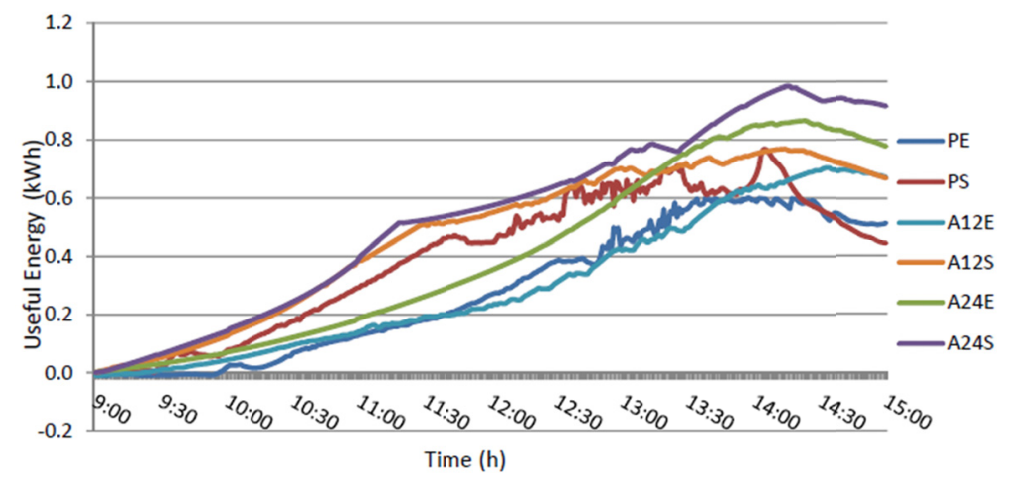

Figure 28. Useful Energy in all the scenarios

According to Figure 28, considering the behavior of the thermal energy gain over the period trailed, it can be observed that the systems with solar tracker presented, for the most part of the time, superiority in the energy utilization in relation to the stationary systems. Within this scope, it can be observed that the system A24S > A12S $>$ PS in the thermal energy gain aspect. As for the stationary systems, the system with the highest heat grain was the A24E system, while the others (A12E and PE) had a similar energy gain.

As shown in Figure 28, it can be observed that in relation to the heating system, the active scenarios (water pumping) presented values of Useful Energy higher than the passive systems (operated with thermosyphon). In general, this relationship was evident as much in the systems with solar tracker as in the stationary, with the exception of A12E and PE systems, which presented energy gains with similar indices. 


\subsubsection{Efficiency of the Systems}

The efficiencies of the systems (obtained from Equation 1) were separated into two groups: efficiencies of the systems with solar tracker and systems with stationary solar orientation. Figure 29 presents the behavior of the efficiencies in the solar tracker systems.

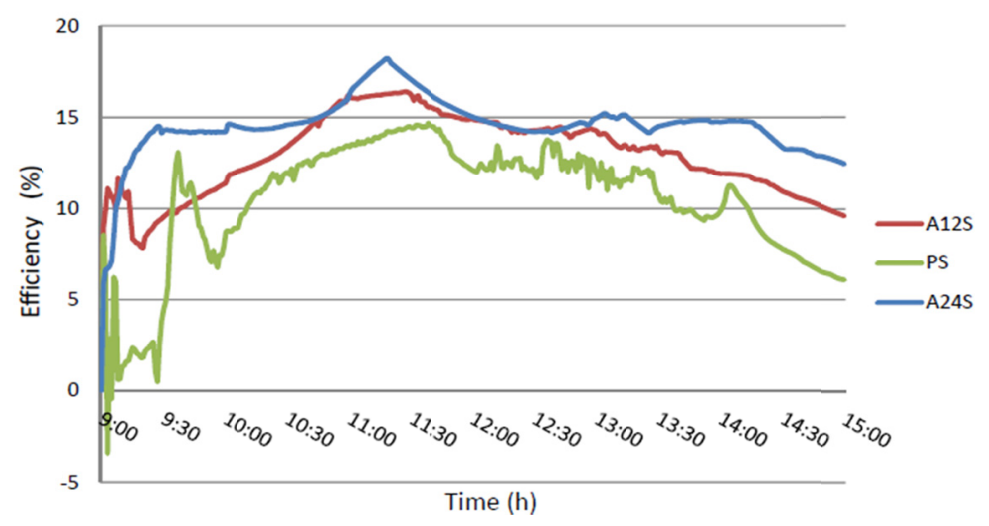

Figure 29. Behavior of the efficiencies in the solar tracker scenarios

According to Figure 29, it is notable that the scenarios composed for active solar heating systems are more efficient than the passive systems. Another important factor is that in the active heating systems the thermal stratification is drastically reduced to the point of being practically empty. Thus, as observed by Hussain and Lee (2014), in a conical solar collector, the mass flow is directly proportional to the system efficiency up to a critical value $(6 \mathrm{~L}$ $\mathrm{min}^{-2}$ ) and is still inversely proportional to the thermal stratification. Also, in relation to Figure 29, it is important to highlight that the system with the highest mass flow has higher efficiency, that is, the efficiency in the A24S > A12S > PS system. The average values of efficiency were $14.53 ; 12.93$ and $10.42 \%$ and presented maximum efficiency of $18.26 ; 16.41$ and $14.70 \%$ respectively for the A24S, A12S and PS systems.

Although the average efficiency values presented are relatively low, in an experiment using a solar collector with a conical concentrator, under active system and solar tracker for water heating (Kaiyan et al., 2009), obtained an average value of efficiency close to $22 \%$. However, the efficiency values discussed here come from experiments of systems with the aims of research, which were not manufactured with precise industrial processes.

Figure 30 presents the result of the efficiencies for the systems trailed with fixed solar orientation.

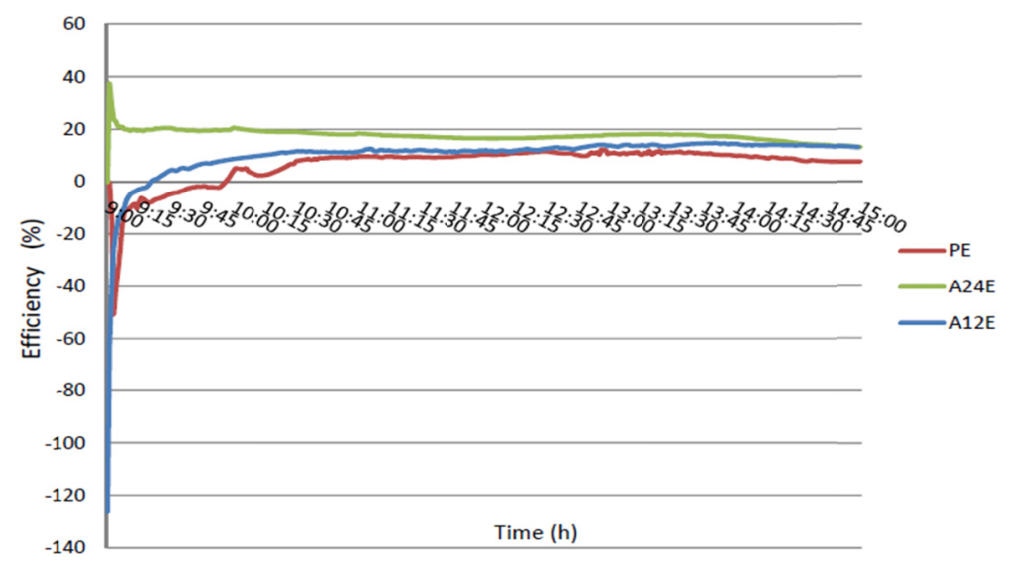

Figure 30. Behavior of the efficiencies in the scenarios with fixed solar orientation

As observed in Figure 30, the hierarchy of the efficiencies in fixed solar orientation systems follows the same trend as the solar tracker systems. In other words, the systems that present higher values of mass flow were more 
efficient. It is noteworthy that the efficiency in the systems with fixed orientation showed smaller variations over the time, compared to the systems operated with solar tracker. The average values of efficiency presented in Figure 30 were $17.69 ; 10.05$ and $6.59 \%$ and presented maximum efficiency of $37.54 ; 14.82$ and $12.38 \%$ respectively for the A24E, A12E and PE systems.

However, in relation to the efficiency of all the trailed scenarios, it is verified that the systems with solar tracker showed higher values of average and maximum efficiency in relation to the fixed guidance systems, except the A24S system.

Knowing that the efficiency is a relation between useful energy and accumulated solar radiation, it can be noticed in Figures 27 and 28, that the solar radiation harnessed by the A24S system is larger than that harnessed by the A24E system. However, the useful energy gains, although they have the same tendency (A24S $>$ A24E), are not as expressive as the harnessed solar radiation.

The heat losses that occur in the evaluated heating systems, responsible for the low efficiencies, are due to the lack of adequate thermal isolation in the reservoir and in the pipes.

A study was developed with a heating system working with different mass flow, in order to obtain the system efficiency (Pereira et al., 2006). It was developed a solar air heater through least-squares support vector machines, and obtained an efficiency that varied from 0.09 to 0.17 , for an air mass flow rate of $0.03 \mathrm{~kg} \mathrm{~s}^{-1}$, and an efficiency that varied from 0.35 to 0.55 , for an air mass flow rate of $0.05 \mathrm{~kg} \mathrm{~s}^{-1}$.

An experimental investigation was developed for analyzing the thermal performance of a double-flow solar air heater having aluminum cans (Esen et al., 2009). The efficiency obtained for $0.05 \mathrm{~kg} \mathrm{~s}^{-1}$ air mass flow varied from 0.3 to 0.8 , and for $0.03 \mathrm{~kg} \mathrm{~s}^{-1}$, varied from 0.2 to 0.6 .

\section{Conclusions}

The solar collector developed in this work has proved technically feasible for water heating, reaching considerable temperatures for the use in residences.

The results showed that the scenarios with solar tracking presented an average efficiency of $12.63 \%$, which was more efficient than those presented by the fixed orientation, which was $11.44 \%$.

In general terms, considering the variables analyzed and the results of the tests performed, it can be concluded that:

i) The geometry of the concentrator set and absorber was effective to provide thermal energy gains for the fluid, even in periods where the concentrator capture plane is not perpendicular to the direction of the flow of the incident solar rays;

ii) Solar water heating systems operated with solar tracker show more efficiency in relation to the stationary systems;

iii) Active solar heating systems are more efficient than the passive systems operated by thermosyphon;

iv) It can be increased the efficiency of active solar heating systems by raising the mass flow to a critical value.

For future studies, it is recommended an evaluation of conical solar collector efficiency with automatic solar tracker, a study of the conic concentrator geometry for different angles, an analysis of the thermal efficiency behavior for a wider range of water flows, and a simulation of the optical behavior for stationary solar concentrators.

\section{Acknowledgements}

This study was financed in part by the Coordenação de Aperfeiçoamento de Pessoal de Nível Superior, Brasil (CAPES).

\section{References}

Aldabó, R. (2002). Energia solar (p. 155). São Paulo: Artliber.

Ali, I. M. S., O’Donovan, T. S., Mallick, T. K., \& Reddy, K. S. (2012). Optical performance of circular and elliptical 3-d estatic solar concentrator. American Solar Energy Society Conference. Retrieved from https://ases.conference-services.net/resources/252/2859/pdf/SOLAR2012_0388_full\%20paper.pdf

ANEEL (Agência Nacional de Energia Elétrica). (2014). Energia solar. Retrieved from http://www.aneel.gov.br/ aplicacoes/atlas/pdf/03-Energia_Solar(3).pdf 
Balghouthi, M., Ali, A. B. H., Trabelsi, S. E., \& Guizani, A. (2014). Optical and termal evaluations of a medium temperature parabolic trough solar collector used in a cooling installation. Conversion and Management, 86, 1134-1146. https://doi.org/10.1016/j.enconman.2014.06.095

Cobble, M. H. (1963). Analysis of a conical solar concentrator. Solar Energy, 7(2), 75-78. https://doi.org/10. 1016/0038-092X(63)90007-0

Darkoptimism. (2015). Concentrating Solar Thermal Power (CSP). Retrieved from http://www.darkoptimism. org/2008/05/19/concentrating-solar-thermal-power-csp

DGS. (2005). Planning and installing solar thermal systems: A guide for installers, architects, and engineers. Deutsche Gesellschaft für Sinnenenergie. German Solar Energy Society. James \& James Ltd., UK and USA.

Duffie, J. A., \& Beckman, W. (2006). A Solar engineering of thermal processes (3rd ed., p. 908). Hoboken: Wiley.

El-Refaie, M. F. (1982). Theoretical analysis of the performance of a conical solar concentrator. Applied Energy, 12, 37-51. https://doi.org/10.1016/0306-2619(82)90030-7

Esen, H., Ozgen, F., Esen, M., \& Sengur, A. (2009). Modeling of a new solar air heater through least-squares support vector machines. Expert Systems with Applications, 36, 10673-10682. https://doi.org/10.1016/ j.eswa.2009.02.045

Fernández-Gárcia, A., Zarza, E., Valenzuela, L., \& Pérez, M. (2010). Parabolic-trough solar collectors and their applications. Renewable and Sustainable Energy Reviews, 14, 1695-1721. https://doi.org/10.1016/j.rser. 2010.03.012

Global Nevadacorp. (2015). Las Vegas Corporate Headquaters. Retrieved from http://globalnvcorp.com/ divisions/energy/solar

Hernández, N., Riveros-Rosas, D., Venegas, E., Dorantes, R. J., Rojas-Hussain, M. I., \& Lee, G. H. (2014). Thermal performance evaluation of a conical solar water heater integrated with a termal storage system. Energy Conversion and Management, 87, 267-273. https://doi.org/10.1016/j.enconman.2014.07.023

Hussain, M. I., \& Lee, G. H. (2014). Thermal performance evaluation of a conical solar water heater integrated with a termal storage system. Energy Conversion and Management, 87, 267-273. https://doi.org/10.1016/ j.enconman.2014.07.023

IAPAR (Instituto Agronômico do Paraná). (2014). Retrieved from http://www.iapar.br/arquivos/Image/monitora mento/Medias_Historicas/Francisco_Beltrao.htm

Kaiyan, H., Hogfei, Z., Tao, T., \& Xiaodi, X. (2009). Experimental investigation of high temperature congregating energy solar stove with sun light funnel. Energy Conversion and Management, 50, 3051-3055. https://doi.org/10.1016/j.enconman.2009.08.009

Kalogirou, S. (2009). Solar energy engineering: processes and systems (p. 756). San Diego: Elsevier.

Luiz, A. M. (2013). Energia solar e preservação do meio ambiente (p. 255). São Paulo: LF editorial.

Mourão, R. R. F. (2007). Sol e energia no terceiro milênio (p. 114). São Paulo: Scipione.

Ozgen, F., Esen, M., \& Esen, H. (2009). Experimental investigation of thermal performance of a double-flow solar air heater having aluminum cans. Renewable Energy, 34, 2391-2398. https://doi.org/10.1016/j.renene. 2009.03.029

Pereira, E. B., Martins, F. R., Abreu, S. L., \& Ruther, R. (2006). Atlas brasileiro de energia solar (p. 60). São José dos Campos: INPE.

Pinho, J. T., \& Galdino, M. A. (2014). Manual de engenharia para sistemas fotovoltaicos (p. 530). CEPEL.

Renewable Power News. (2009). DII GmbH, a radical emerge and initiative for sustainable solar energy. Retrieved from http://renewablepowernews.com/archives/422

Rustemli, S., Dincer, F., Unal, E., Karaaslan, M., \& Sabah, C. (2013). The analysis on sun tracking and cooling systems for fotovoltaic panels. Renewable and Sustainable Energy Reviews, 22, 598-603. https://doi.org/ 10.1016/j.rser.2013.02.014

Sharaf, E. (2002). A new design for an economical, highly efficient, conical solar cooker. Renewable Energy, 27, 599-619. https://doi.org/10.1016/S0960-1481(01)00136-7 
Togrul, I. T., \& Pehlivan, D. (2003). The performance of a solar air heater with conical concentrator under forced convection. International Journal of Thermal Science, 42, 571-581. https://doi.org/10.1016/S12900729(03)00023-1

Walisiewicz, M. (2008). Energia alternativa: solar, eólica, hidrelétrica e de biocombustíveis (p. 72). São Paulo: Publifolha.

Wijeysundera, N. (1977). E. Effect of angular misorientation on the performance of conical, spherical and parabolic solar concentrator. Solar Energy, 19, 583-588. https://doi.org/10.1016/0038-092X(77)90118-9

Xião, X., Zhang, P., Shao, D. D., \& Li, M. (2014). Experimental and numerical heat transfer analisys of a V-cavity absorber for linear parabolic trough solar collector. Energy Conversion and Management, 86, 49-59. https://doi.org/10.1016/j.enconman.2014.05.001

Xiaodi, X., Hongfei, Z., Kaiyan, H., Zhili, C., Tao, T., \& Guo, X. (2010). Experimental study on a new solar boiling water system with holistic track solar funnel concentrator. Energy, 35, 692-697. https://doi.org/ 10.1016/j.energy.2009.10.033

Zahedi, A. (2011). Review of modeling details in relation to low-concentration solar concentrating photovoltaic. Renewable and Sustainable Energy Reviews, 15, 1609-1614. https://doi.org/10.1016/j.rser.2010.11.051

Zheng, H., Wu, G., Tao, T., Su, Y., \& Dai, J. (2014). Combination of a light funnel concentrator with a deflector for orientated sunlight transmission. Energy Conversion and Management, 88, 785-793. https://doi.org/ 10.1016/j.enconman.2014.09.004

\section{Copyrights}

Copyright for this article is retained by the author(s), with first publication rights granted to the journal.

This is an open-access article distributed under the terms and conditions of the Creative Commons Attribution license (http://creativecommons.org/licenses/by/4.0/). 